\title{
¿Es el Código OrgánICo deL AMBIENTE EL NUEVO DRIVER CONTRA IA CONSERVACIÓN DE LA BIODIVERSIDAD?
}

\section{Mónica Ribadeneira Sarmiento}

Investigadora independiente

Quito, Ecuador.

Correo electrónico: mribadeneira@hotmail.com; mribadeneira@gmail.com

Recibido / Received: 12/03/2019

Aceptado / Accepted: 26/03/2019

DOI: 10.18272/lr.v6i1.1404

\section{Citación}

Ribadeneira Sarmiento, M. «¿Es El Código Orgánico Del Ambiente El Nuevo Driver Contra La conservación De La Biodiversidad?». USFQ Law Review, Vol. 6, n. ${ }^{\circ}$ 1, agosto de 2019, p. 20 , doi:10.18272/lr.v6i1.1404. 


\section{RESUMEN}

El Código Orgánico del Ambiente fue promulgado en 2017 y debía entrar en vigencia un año después. Este artículo reseña las principales deficiencias técnicas de dicho cuerpo legal relacionadas con la conservación de la biodiversidad, los temas forestales, los manglares, las cuencas hidrográficas y la reparación de daños ambientales.

En este artículo se explica cómo estas deficiencias, lejos de colaborar con la conservación de la biodiversidad nacional, debilitan la estructura institucional y complejizan el manejo de los recursos de la diversidad biológica, constituyéndose el instrumento legal en un driver contra la conservación de la biodiversidad nacional.

\section{Palabras Clave}

Derecho Ambiental; Derecho Constitucional; Código Orgánico del Ambiente; conservación de la diversidad biológica; forestal; manglares; cuencas hidrográficas; reparación daño ambiental

\section{Is the Ecuadorian Organic Code of the Environment the new driver against the conservation of biodiversity?}

\section{Abstract}

The Ecuadorian Environmental Organic Code was promulgated in 2017 and had to enter into force a year later. This article outlines the main technical deficiencies of the code in the areas of biodiversity conservation, forest issues, mangroves, watersheds, and restoration of environmental damage.

The article presents how these deficiencies far from supporting the conservation of the national biodiversity, weaken the institutional structure and makes more complex the conservation of biodiversity; this confirms the legal instrument as a driver against the biological diversity conservation.

\section{KEYWORDS}

Environmental law; Constitutional Law; Environmental Organic Code; conservation of biological diversit; forestry; mangroves; watershed; environmental damage repair 


\section{INTRODUCCIÓN}

Tras una revisión del Código Orgánico del Ambiente (en adelante COA) después de su promulgación en 2017, se alertó a la Coordinadora Ecuatoriana de Organizaciones para la Defensa de la Naturaleza y Ambiente (en adelante Cedenma) sobre varias de las deficiencias técnicas y potenciales problemas en su texto. Este fue el motivo para iniciar un proceso de análisis legal tendiente a la presentación de acciones en sede constitucional contra el cuerpo legal que lograra, de un lado, visibilizar las deficiencias de este instrumento legal y de otro, propiciar que la Corte Constitucional pudiera subsanarlas ${ }^{1}$.

Con este fin, convocó a varios abogados ambientales e instituciones interesadas, y asumió las tareas de secretaría de lo que se denominó "grupo de trabajo COA".

Este grupo trabajó desde febrero de 2017 hasta mayo de 2018 cuando presentó dos acciones de inconstitucionalidad ante la Corte Constitucional, una el día 5 y la segunda el día 13 de junio de 2018. La primera acción acusó la inconstitucionalidad de: (i) la regresividad de las normas sobre actividades permitidas en los manglares ${ }^{2}$; (ii) la posibilidad de establecimiento de monocultivos ${ }^{3}$; (iii) la limitación al derecho de participación ciudadana en materia ambiental ${ }^{4}$; y, (iv) la imposibilidad de imposición de sanción administrativa en caso de captura de productos forestales y maderables 5 . La segunda acción se planteó contra las normas que atentan contra los derechos de los pueblos indígenas en general y contra los pueblos en aislamiento voluntario en particular; el análisis completo sobre la segunda acción de inconstitucionalidad es materia de otra investigación ${ }^{6}$.

Las deficiencias, incongruencias, vacíos y errores en el texto del COA que se evidenciaron durante su análisis son el objeto de este artículo.

1 Rueda de prensa de Cedenma y otros en la presentación de la primera acción de inconstitucionalidad contra el COA el día 5 de junio de 2018. Disponible en: https://www.facebook.com/CEDerechosHUmanos/videos/1688490821233527/. Fecha de la descarga: 25 de noviembre de 2018

2 "Art. 104.- Actividades permitidas en el ecosistema de manglar. Las actividades permitidas en el ecosistema de manglar, a partir de la vigencia de esta ley, serán las siguientes:

7. Otras actividades productivas o de infraestructura pública que cuenten con autorización expresa de la Autoridad

Ambiental Nacional y que ofrezcan programas de reforestación." (COA. Artículo 104. Registro Oficial No. 983 Suplemento de 12 de abril de 2017)

3 "Art. 121.- Monocultivos. Se podrán establecer monocultivos en las plantaciones forestales realizadas en áreas degradadas o en proceso de desertificación determinadas en el plan de ordenamiento territorial”. (Eiusdem. Artículo 121.)

4 "Art. 184.- De la participación ciudadana. La Autoridad Ambiental Competente deberá informar a la población que podría ser afectada de manera directa sobre la posible realización de proyectos, obras o actividades, así como de los posibles impactos socioambientales esperados y la pertinencia de las acciones a tomar. La finalidad de la participación de la población será la recolección de sus opiniones y observaciones para incorporarlas en los Estudios Ambientales, siempre que ellas sean técnica y económicamente viables.

Si del referido proceso de consulta resulta una oposición mayoritaria de la población respectiva, la decisión de ejecutar o no el proyecto será adoptada por resolución debidamente motivada de la Autoridad Ambiental Competente.

En los mecanismos de participación social se contará con facilitadores ambientales, los cuales serán evaluados, calificados y registrados en el Sistema Único de Información Ambiental." (Eiusdem. Artículo 184.)

5 "Art. 320.- Sanciones administrativas.- Son sanciones administrativas las siguientes: 2. Decomiso de las especies de vida silvestre, nativas, exóticas o invasoras, herramientas, equipos, medios de transporte y demás instrumentos utilizados para cometer la infracción". (Eiusdem. Artículo 320.)

6 Ribadeneira Sarmiento, Mónica. La defensa ambiental y de los derechos humanos de los pueblos en aislamiento voluntario en sede constitucional, un ejemplo. 2018. Presentado; actualmente en proceso de revisión. 


\section{El Código Orgánico del Ambiente}

El COA fue promulgado en 2017, concretamente se publicó en el Suplemento al Registro Oficial No. 983 del 12 de abril de ese año, pero, en vista de una disposición transitoria que establece una vacatio legis de un $\mathrm{ańo}^{7}$, se esperaba que su implementación sucediera en febrero 2018.

El proceso de reglamentación, cronograma incluido, que el Ministerio del Ambiente (en adelante MAE) había estimado no se cumplió, y hasta el momento de escribir este artículo ${ }^{8}$ no se cuenta con un reglamento de aplicación general y peor con reglamentos para materias específicas. Amén de la gravedad de contar con un cuerpo legal sin instrumentos de aplicación, el COA es en sí mismo un driver ${ }^{9}$ en contra de la conservación de la diversidad biológica ${ }^{10}$ nacional, tal como concluye esta investigación.

El código comienza con cincuenta y nueve considerandos y está organizado en ocho libros, uno preliminar, otro dedicado al régimen institucional, el siguiente al patrimonio natural (el más extenso de todos) que precede a los libros dedicado a la calidad ambiental, al cambio climático y a la zona marino costera para concluir con los libros dedicados a los incentivos ambientales y a la reparación integral de daños ambientales y régimen sancionador. Contiene dos disposiciones generales, catorce transitorias, siete derogatorias y una final ${ }^{11}$, a más de un glosario de cincuenta y dos términos ${ }^{12}$.

\subsection{Principales deficiencias temáticas del COA}

Debido a la limitación de la extensión de este artículo, no es posible hacer un recuento exhaustivo de este cuerpo legal que permita presentar todas sus deficiencias.

En vista de que Ecuador es uno de los países con mayor riqueza de diversidad biológica en el planeta que incluye desde bosques húmedos a nublados y secos, incluyendo manglares y páramos, además de cientos de lagunas, formaciones coralinas y ecosistemas únicos como los de Galápagos, y junto a esta riqueza, tam-

\footnotetext{
7 "Disposición Final Única.- El Código Orgánico del Ambiente entrará en vigencia luego de transcurridos doce meses, contados a partir de su publicación en el Registro Oficial”. (COA. Eiusdem. Disposición final única.)

8 Febrero de 2019.

9 Del original en inglés, driver en su acepción "impulso o causante"; en las publicaciones técnicas en castellano se emplea de igual manera y con igual significado.

10 "Artículo 2. Términos utilizados. A los efectos del presente convenio: [...]

Por "diversidad biológica» se entiende la variabilidad de organismos vivos de cualquier fuente, incluidos, entre otras cosas, los ecosistemas terrestres y marinos y otros ecosistemas acuáticos y los complejos ecológicos de los que forman parte; comprende la diversidad dentro de cada especie, entre las especies y de los ecosistemas. (Convenio sobre la Diversidad Biológica. Registro Oficial No. 109 de 18 de enero de 1993 y Registro Oficial No. 146 de 16 de marzo de 1993).

11 El contenido de las disposiciones del COA puede ser consultado en el Anexo No. 1 del presente artículo. COA. Eiusdem. Disposiciones generales, transitorias y final única.

12 COA. Eiusdem. Glosario de Términos
} 
bién posee una extraordinaria diversidad étnica y cultural ${ }^{13}$, se seleccionó como materias principales a: (i) conservación de la diversidad biológica, (ii) materia forestal, (iii) manglares, (iv) cuencas hidrográficas, y (v) reparación de daños ambientales.

A continuación, se presenta las deficiencias del COA en cada una de estas materias.

\subsubsection{CONSERVACIÓN DE LA DIVERSIDAD BIOLÓgICA}

La conservación de la diversidad biológica o biodiversidad se puede hacer en el entorno o hábitats naturales, caso en que se denomina conservación in situ ${ }^{14} \mathrm{y}$ en condiciones especiales o fuera de su entorno natural, situación que se denomina conservación ex situ ${ }^{15}$.

El mecanismo más efectivo e importante de la conservación in situ es el establecimiento de áreas naturales protegidas que, en la Constitución ecuatoriana, fue denominado Sistema Nacional de Áreas Naturales Protegidas (en adelante SNAP) ${ }^{16}$. Este sistema engloba cuatro subsistemas: (i) estatal, (ii) autónomo descentralizado, (iii) comunitario y (iv) privado. En relación con el primero de estos subsistemas, el estatal, también llamado Patrimonio de Áreas Naturales Protegidas ${ }^{17}$ (en adelante PANE), las categorías que determina el COA son: (i) parque nacional, (ii) refugio de vida silvestre, (iii) reserva de producción de fauna, (iv) área de recreación, y (v) reserva marina.

Las áreas del PANE, y aún del SNAP comparten, en mayor o menor grado, una problemática caracterizada por: (i) asentamientos humanos y propiedad privada en su interior, que no están integradas al manejo del área; (ii) obras de infraes-

13 Ecuador se encuentra en la privilegiada lista de las 17 naciones megadiversas en el mundo, es decir los países con mayor riqueza de animales, plantas y microorganismos en el planeta; y si miramos esta misma clasificación desde un análisis por unidad de superficie, resulta ser el primero. Junto a esta riqueza, Ecuador posee una extraordinaria diversidad étnica y cultural.

En Ecuador, esta característica se debe principalmente a la combinación de: (i) gradiente altitudinal creada por la cordillera de los Andes, que provoca la existencia de un sin número de ambientes y especies; (ii) ubicación del país en la zona tropical; y, (iii) existencia de corrientes cálidas y frías que bańan nuestras costas. (Estrella J., Manosalvas R., Mariaca J. y Ribadeneira Sarmiento M. Biodiversidad y recursos genéticos: una guía para su uso y acceso en el Ecuador. Quito: Ecociencia, Iniap, MAE y Abya-Yala, 2005.)

14 Artículo 2. Términos utilizados. A los efectos del presente convenio: [...]

Por "condiciones in situ» se entienden las condiciones en que existen recursos genéticos dentro de ecosistemas y hábitats naturales y, en el caso de las especies domesticadas o cultivadas, en los entornos en que hayan desarrollado sus propiedades específicas. Convenio sobre la Diversidad Biológica. (Eiusdem. Artículo 2.)

15 Artículo 2. Términos utilizados. A los efectos del presente convenio: [...]

Por «conservación ex situ» se entiende la conservación de componentes de la diversidad biológica fuera de sus hábitats naturales". Eiusdem.

16 Título VII: Régimen del Buen Vivir. Capítulo II: Biodiversidad y recursos naturales. Sección III: Patrimonio natural y ecosistemas Art. 405.- El sistema nacional de áreas protegidas garantizará la conservación de la biodiversidad y el mantenimiento de las funciones ecológicas. El sistema se integrará por los subsistemas estatal, autónomo descentralizado, comunitario y privado, y su rectoría y regulación será ejercida por el Estado. El Estado asignará los recursos económicos necesarios para la sostenibilidad financiera del sistema, y fomentará la participación de las comunidades, pueblos y nacionalidades que han habitado ancestralmente las áreas protegidas en su administración y gestión.

Las personas naturales o jurídicas extranjeras no podrán adquirir a ningún título tierras o concesiones en las áreas de seguridad nacional ni en áreas protegidas, de acuerdo con la ley. (Constitución. Constitución de la República del Ecuador. Artículo 405. Registro Oficial No. 449 de 20 de octubre de 2008.)

17 Establecido de conformidad con la Ley Forestal, de Áreas Protegidas y de Vida Silvestre del año 1981, derogada por el COA. 
tructura que provocan graves impactos ambientales que amenazan su integridad; (iii) limitaciones de carácter técnico como falta de personal profesional y técnico especializado, al igual que procesos de capacitación y formación sostenidos dirigidos al personal de guardaparques y estudiosos; y, (iv) deficiencias económicas y administrativas que limitan la capacidad para su gestión y manejo ${ }^{18}$. Aunque la falta de marco legal adecuado no es la causa directa de esta problemática, no puede desconocerse que su falta incide en ella. Por ello, era de esperarse que el COA atendiera esta variopinta problemática, pero no sucedió así.

El COA no define ninguna de las categorías de área protegida; lo cual no solo constituye una seria deficiencia sino también un riesgo técnico y legal, ya que las definiciones no serán conceptos legales sino meramente reglamentarios, cuya seguridad jurídica dependerá de acto normativo reglamentario, no legal. En este aspecto es necesario reiterar que el COA, al no establecer un objeto jurídico de protección ni su sistema de determinación, pone en riesgo los bienes y servicios de la biodiversidad y los somete a inseguridad jurídica y arbitrariedad administrativa. Las segunda y tercera deficiencia del COA en materia de áreas protegidas se encuentran al hacer una lectura que enfrente los artículos $5^{19}$ y $37^{20}$, y a ambos con el $407^{21}$ de la Constitución.

Como puede verse, el artículo 5 numeral 3 consagra la intangibilidad del SNAP, pero el artículo 37 último inciso establece la posibilidad de redelimitar o reclasificar entre categorías de manejo. Aunque, en primera instancia, la redeli-

18 Ribadeneira Sarmiento, Mónica. Documento Conceptual sobre el Anteproyecto de Ley Especial para la conservación y Uso Sustentable de la Biodiversidad del Ecuador. CLD, Cedenma, Ecociencia, Fundación Natura y MAE. 2001. Inédito.

19 "Art. 5.- Derecho de la población a vivir en un ambiente sano. El derecho a vivir en un ambiente sano y ecológicamente equilibrado comprende: $[\ldots]$

3. La intangibilidad del Sistema Nacional de Áreas Protegidas, en los términos establecidos en la Constitución y la ley". (COA. Eiusdem. Artículo 5.)

20 Art. 37.- Del Sistema Nacional de Áreas Protegidas. El Sistema Nacional de Áreas Protegidas estará integrado por los subsistemas estatal, autónomo descentralizado, comunitario y privado. Su declaratoria, categorización, recategorización, regulación y administración deberán garantizar la conservación, manejo y uso sostenible de la biodiversidad, así como la conectividad funcional de los ecosistemas terrestres, insulares, marinos, marino-costeros y los derechos de la naturaleza.

Las áreas protegidas serán espacios prioritarios de conservación y desarrollo sostenible. Los Gobiernos Autónomos Descentralizados deberán incorporar las áreas protegidas a sus herramientas de ordenamiento territorial.

En las áreas protegidas se deberán establecer limitaciones de uso y goce a las propiedades existentes en ellas y a otros derechos reales que sean necesarias para asegurar el cumplimiento de sus objetivos de conservación. El Estado evaluará, en cada caso, la necesidad de imponer otras limitaciones.

Se prohíbe el fraccionamiento de la declaratoria de áreas protegidas.

Sin perjuicio de lo anterior, los posesionarios regulares o propietarios de tierras dentro de un área protegida, que lo sean desde antes de la declaratoria de la misma, mantendrán su derecho a enajenar, fraccionar y transmitir por sucesión estos derechos sobre estas tierras. Con respecto del fraccionamiento de tierras comunitarias se observarán las restricciones constitucionales.

El Estado asignará los recursos económicos necesarios para la sostenibilidad financiera del Sistema Nacional de Áreas Protegidas. Se podrán gestionar estrategias y fuentes complementarias.

La Autoridad Ambiental Nacional realizará evaluaciones técnicas periódicas con el fin de verificar que las áreas protegidas cumplan con los objetivos reconocidos para las mismas. De ser necesario y considerando los resultados de dichas evaluaciones técnicas, la Autoridad Ambiental Nacional podrá redelimitarlas o cambiarlas de categoría bajo las consideraciones técnicas, según corresponda. (Eiusdem. Artículo 37.)

21 "Título VII: Régimen del Buen Vivir. Capítulo Segundo: Biodiversidad y Recursos Naturales. Sección Tercera: Patrimonio Natural y Ecosistemas.

Art. 407.- Se prohíbe la actividad extractiva de recursos no renovables en las áreas protegidas y en zonas declaradas como intangibles, incluida la explotación forestal. Excepcionalmente dichos recursos se podrán explotar a petición fundamentada de la Presidencia de la República y previa declaratoria de interés nacional por parte de la Asamblea Nacional, que, de estimarlo conveniente, podrá convocar a consulta popular”. Constitución de la República del Ecuador. (Eiusdem. Artículo 407.) 
mitación o reclasificación puede ser técnicamente posible y hasta recomendable, cabe preguntarse cómo será ello posible sin alterar la intangibilidad que establece como principio el COA. Ningún principio o elemento del texto de este instrumento legal permite adelantar una respuesta a esta interrogante.

Si a este enfrentamiento de dos artículos de este código se le contrapone el artículo 407 de la Constitución, con el que se supone debe guardarse lógica en razón de la jerarquía de instrumentos legales se puede fácilmente arribar al temor fundado de que la redelimitación o reclasificación sea solamente un instrumento "eficiente" para aplicar la discrecionalidad de la Presidencia de la República y su potestad de declarar áreas de interés nacional en cualquier área del PANE, del SNAP y aún de las zonas intangibles declaradas a favor de pueblos indígenas y en aislamiento voluntario.

Esto último no solo es posible sino altamente probable ya que los artículos $53^{22}$ y $54^{23}$ del COA contribuyen y refuerzan la remisión a la norma constitucional, que debilita las posibilidades de conservación. La historia ecuatoriana cuenta con suficientes y lamentables casos que evidencian que los intereses económicos y políticos han prevalecido frente a los intereses de la conservación ambiental.

En relación con la redelimitación o reclasificación, cabe mencionar que todas las vigentes áreas y categorías de manejo del actual $\mathrm{PANE}^{24}$ deben pasar por un proceso de reclasificación, tema al que se refiere la Disposición Transitoria Sexta ${ }^{25}$ sin que exista ninguna norma orientadora como no sea la de la intangibilidad del citado artículo 5 numeral 3 que motiva los anotados interrogante y temor.

22 "Art. 53.- De las obras, proyectos o actividades dentro del Sistema Nacional de Áreas Protegidas. La Autoridad Ambiental Nacional autorizará obras, proyectos o actividades dentro del Sistema Nacional de Áreas Protegidas de manera excepcional, siempre que se cumplan las condiciones de no afectar la funcionalidad del área protegida, estar de acuerdo al plan de manejo y zonificación del área protegida y no contrariar las prohibiciones y restricciones previstas en la Constitución y en este Código". (COA. Eiusdem. Artículo 53.)

23 "Art. 54.- De la prohibición de actividades extractivas en áreas protegidas y zonas intangibles. Se prohíben las actividades extractivas de recursos no renovables dentro del Sistema Nacional de Áreas Protegidas y en zonas declaradas como intangibles, incluida la explotación forestal, salvo la excepción prevista en la Constitución, en cuyo caso se aplicarán las disposiciones pertinentes de este Código". (Eiusdem. Artículo 54.)

24 Actualmente, el PANE se conforma de cincuenta áreas clasificadas en ocho categorías: (i) once parques nacionales, (ii) tres reservas marinas, (iii) nueve reservas ecológicas, (iv) cinco reservas biológicas, (v) cinco reservas de producción de fauna, (vi) una reserva geobotánica, (vii) diez refugios de vida silvestre, y (viii) seis áreas naturales de recreación. Hay seis áreas restantes que pertenecen a las subcategorías de áreas privada y comunitarias. Ministerio del Ambiente. http://areasprotegidas.ambiente.gob.ec/es/info-snap. (acceso 23/02/2019).

25 "Disposición Transitoria Sexta.- La Autoridad Ambiental Nacional realizará la evaluación del estado de conservación de la biodiversidad, cobertura, uso de suelo, amenazas, entre otros, de las áreas que conforman el Sistema Nacional de Áreas Protegidas y Patrimonio Forestal Nacional.

La evaluación de las áreas protegidas se realizará dentro del plazo de 4 años a partir de la publicación de este Código en el Registro Oficial y servirá para delimitarlas o cambiarlas de categoría, según corresponda, con el fin de que cumplan los objetivos establecidos en el Libro II de este Código.

En el caso del Patrimonio Forestal Nacional, la Autoridad Ambiental Nacional, en coordinación con la Autoridad Nacional de Agricultura, Ganadería, Acuacultura y Pesca, en el marco de sus competencias, dentro del plazo establecido anteriormente, realizará una actualización del estado de estos espacios naturales, lo que servirá para la definición de estrategias de conservación, manejo y uso sostenible, restauración, modificación de sus límites o la eliminación de la categoría de Patrimonio Forestal Nacional, según corresponda”. (COA. Eiusdem. Disposición transitoria sexta.) 
Debido a la extensión de este trabajo de investigación es imposible profundizar en los problemas de la tenencia de la tierra en las áreas del SNAP y en las disposiciones que el COA contiene a este respecto. Este y otros temas serán analizados en otra investigación.

Las incompatibilidades de este instrumento legal con los derechos humanos de los pueblos no contactados y que motivaron una acción constitucional de protección son materia de otra investigación como se adelantó al inicio de este artículo.

\subsubsection{MATERIA FORESTAL}

En materia forestal, se encuentran varios errores y deficiencias en el COA. En los apartados a continuación se presenta el análisis de aquellos relativos a la falta de lógica y de técnica, dispersión de autoridades y una específica relacionada a los monocultivos.

\subsubsection{FALTA DE LÓgica}

El artículo noventa y tres, que trata sobre la gestión del patrimonio forestal, contiene una afirmación falta de lógica porque sostiene que la degradación ${ }^{26}$ de suelos es ilegal ${ }^{27}$. La degradación es un proceso de reducción, limitación y alteración de las funciones naturales que no es una actividad directa; es resultado y consecuencia de actividades ilegales y desatinadas como los monocultivos (promovidos por el artículo $121^{28}$ ), uso abusivo de pesticidas y otras actividades.

\subsubsection{DISPERSIÓN DE AUTORIDADES Y COMPETENCIAS}

Una de las lamentables características del marco legal ambiental en Ecuador es la superposición de competencias entre instituciones estatales, debido a la promulgación de leyes sin el debido análisis y de la vigencia de ciertas instituciones y procedimientos no necesariamente integrados ni articulados de modo eficiente entre sí. Este ha sido el escenario institucional en que siempre se ha desenvuelto el $\mathrm{MAE}^{29}$.

26 "Degradación (Degradation).- Proceso de reducción o rompimiento de una estructura en piezas más simples. En Ecología de Paisajes describe la reducción de la complejidad en los ecosistemas debido a alteraciones que limitan la función y alteran la forma original". (Sarmiento, Fausto. Diccionario de Ecologia. Quito: Abya Yala, 2000.)

27 "Art. 93.- Gestión del Patrimonio Forestal de la República. La gestión del Patrimonio Forestal Nacional se ejecutará en el marco de las siguientes disposiciones fundamentales: [...]

6. Manejo forestal sostenible. El Régimen Forestal Nacional promoverá el manejo forestal sostenible como estrategia para garantizar el uso racional del bosque nativo excluyendo actividades ilegales como la extracción, degradación y deforestación". (COA. Eiusdem. Artículo 93.)

28 Para profundizar este tema ver el apartado 2.1.2.3. de este artículo.

29 Entre los cuales se puede citar:

la adscripción al MAE del Instituto Ecuatoriano Forestal y de Áreas Naturales y Vida Silvestre (Inefan), Fondo para el Ecodesarrollo Amazónico, Comisión Asesora Ambienta (CAAM), y la Comisión Ecuatoriana de Energía Atómica, que se realizó mediante Decreto No. 290, publicado en el Suplemento al Registro Oficial No. 64 de 8 de noviembre de 1996; y,

la fusión del Inefan, publicada en el Registro Oficial No. 118 de enero 28 de 1999, Decreto Ejecutivo No. 505.

Además, en enero de 2000 fue unificado con otra cartera de Estado, como prueba de lo susceptible que es el régimen institucional en materia ambiental a las presiones políticas y económicas que siguieron a la caída del presidente Jamil Mahuad. 
En contra de la lógica, el COA no capitaliza las lecciones aprendidas ni la experiencia y su artículo 97 le otorga el manejo forestal al Ministerio de Agricultura ${ }^{30}$.

Otro error en esta misma materia consta en el artículo 93 numeral 4 que se refiere al rol de la Policía y de las Fuerzas Armadas a quienes pone a orden de las autoridades ambientales para respaldo de sus acciones, pero solamente en cuanto a la gestión forestal ${ }^{31}$.

Cabe una observación sobre este numeral y se relaciona con la exclusividad de este rol, solo aplicable para la gestión del patrimonio forestal, no para la custodia de todos los bienes y servicios de la diversidad biológica y de la vida silvestre, no para apoyar las decisiones de la autoridad ambiental en el manejo de los recursos, sino solo para la gestión forestal. Esa exclusión no es inocente, resulta de una agenda cuyos efectos aún no se han podido apreciar.

En vista de que el precepto constitucional sobre las competencias de la Policía y de las Fuerzas Armadas que se refiere a "atender la seguridad ciudadana y el orden público, y proteger el libre ejercicio de los derechos y la seguridad de las personas dentro del territorio nacional"32 sería lógico que las fuerzas del orden apoyen la seguridad y ejecución de las medidas de la autoridad ambiental que así lo requieran.

\subsubsection{MEDIDA PELIGROSA Y CONTRARIA A LA CONSERVACIÓN Y MANEJO DEL PATRIMONIO FORESTAL}

El COA, en su glosario, no contiene una definición de "monocultivos"; sin embargo, el artículo 121 se titula así y determina que los monocultivos se convertirían en opción en lugar de iniciar recuperación o reforestación ${ }^{33}$.

30 "Art. 97.- Autoridad Nacional de Agricultura. La Autoridad Nacional de Agricultura ejercerá la regulación, planificación, promoción, fomento y gestión de plantaciones forestales y sistemas agroforestales de producción y con fines comerciales". (Eiusdem. Artículo 97.)

31 “Artículo 93.- Gestión del Patrimonio Forestal Nacional.- La gestión del Patrimonio Forestal Nacional se ejecutará en el marco de las siguientes disposiciones fundamentales: [...]

4. Obligaciones de la Policía Nacional o de las Fuerzas Armadas. La Policía Nacional y las Fuerzas Armadas tendrán la obligación de participar en el control del Patrimonio Forestal Nacional y prestar auxilio cada vez que lo solicite la Autoridad Ambiental Nacional y las autoridades que ejercen competencia en la gestión forestal. Siempre que la intervención se sujete a los límites establecidos en la Constitución y las leyes, la resolución de la autoridad causará estado de actuación en derecho de las fuerzas intervinientes y sus actos se considerarán como ejercicio regular de sus atribuciones”. (Eiusdem. Artículo 93.)

32 "Título IV: Participación y Organización del Poder. Capítulo tercero: Función Ejecutiva. Sección tercera: Fuerzas Armadas y Policía Nacional

Art. 163.- La Policía Nacional es una institución estatal de carácter civil, armada, técnica, jerarquizada, disciplinada, profesional y altamente especializada, cuya misión es atender la seguridad ciudadana y el orden público, y proteger el libre ejercicio de los derechos y la seguridad de las personas dentro del territorio nacional.

Los miembros de la Policía Nacional tendrán una formación basada en derechos humanos, investigación especializada, prevención, control y prevención del delito y utilización de medios de disuasión y conciliación como alternativas al uso de la fuerza.

Para el desarrollo de sus tareas la Policía Nacional coordinará sus funciones con los diferentes niveles de gobiernos autónomos descentralizados". (Constitución de la República del Ecuador. Eiusdem. Artículo 163.)

33 "Reforestación (Reforestation).- Acto de volver a sembrar árboles, para formar de nuevo una vegetación como la derrumbada o deforestada, con el fin de hacer conservación del suelo, atenuar las manifestaciones climáticas y el secuestro de carbono". (Sarmiento, Fausto. Op. cit.) 
Art. 121.- Monocultivos. Se podrán establecer monocultivos en las plantaciones forestales realizadas en áreas degradadas o en proceso de desertificación determinado en el plan de ordenamiento forestal.

Un monocultivo nunca es una alternativa a la pérdida de valores naturales. El monocultivo es el sistema de un solo cultivo en la misma tierra y año tras año, se define como la "situación de explotación agrícola, que empobrece los elementos del suelo, al tener persistencia en la selectividad mineral de plantas por la repetitividad continuada de la misma especie de planta cultivada durante mucho tiempo" ${ }^{34}$.

En este tipo de plantaciones, que además suelen ser de importantes extensiones, se utilizan los mismos métodos de fertilización y control de pestes para garantizar niveles de producción. Una de las características del monocultivo es que puede alcanzar en un corto tiempo máximo de producción agrícola debido a la adición y concentración de fertilizantes ${ }^{35}$ y otra es su naturaleza como sistema intensivo de producción.

El costo ambiental del monocultivo es muy alto; al empobrecimiento del suelo por desgaste de nutrientes que conduce a la erosión ${ }^{36}$ porque en el monocultivo se cosecha toda la planta, interrumpiendo el proceso natural de reciclaje e incorporación de materia orgánica en el suelo, debe sumarse que generalmente compromete de manera irremediable acuíferos ${ }^{37}$ y fuentes de agua cercanas, que contribuye con la rápida dispersión de enfermedades por falta de defensas naturales y porque algunos insectos encuentran alimento constante en el monocultivo, pocos predadores y se reproducen intensamente, con lo cual se tornan en plagas, empobrecimiento de la biodiversidad porque no puede sustentar a animales que antes habitaban ese sitio (desde insectos hasta mamíferos, incluyendo aves) y estos no pueden alimentarse, encontrar abrigo o refugio, reproducirse ni cumplir con sus servicios ecosistémicos como la polinización y dispersión de semillas.

Las plantaciones forestales aludidas en el artículo 121 son típicamente un monocultivo y sus nefastas consecuencias pueden apreciarse en varias provincias del país.

Es un contrasentido que el COA plantee que "se podrán establecer monocultivos en las plantaciones forestales realizadas en áreas degradadas o en proceso de de-

\footnotetext{
34 Ibid.

35 "Fertilizante (Fertilizer).- Producto químico, usualmente con mezcla Nitrogenada y/o Fosforilada, que enriquece al suelo por el intercambio iónico incrementado y favorece el desarrollo de las plantas y aumenta la producción agrícola”. Ibid.

36 "Erosión (Erosion).- Proceso geológico relacionada con el desgaste y la movilización de los materiales que forman la tierra; se compone de dos fases, a saber: (i) meteorización: donde se destruyen y segregan en partículas cada vez más pequeńas, y (ii) transporte: donde se mueven los sedimentos hacia zonas cada vez más bajas. Ibid. Existen varios tipos de erosión: acelerada, diferencial, difusa, en carcavas, en surcos, laminar, marginal y por salpicadura". Ibid.

37 "Acuífero (Aquifer).- Cualquier material subsuperficial que puede mantener una cantidad significante de agua subterránea y es capaz de transmitirla rápidamente". Ibid.
} 
sertificación determinadas en el plan de ordenamiento territorial"38, ya que las áreas degradadas o en proceso de desertificación ${ }^{39}$ deberían ser objeto de restauración; entendiéndose como restauración "el proceso de asistir la recuperación de un ecosistema que ha sido degradado, dañado o destruido" según la definición internacionalmente aceptada de la Sociedad para la Restauración Ecológica (en adelante SER, del original en inglés Society for Ecological Restauration $)^{40}$.

La restauración ecológica tiene cinco componentes: (i) ecológico, (ii) económico, (iii) social, (iv) cultural y (v) político-legislativo ${ }^{41}$. Desde un punto de vista ecológico, la restauración se fundamenta en los principios dinámicos de molestia ${ }^{42}$, resistencia ${ }^{43}$ y estabilidad de un sistema.

Incluso la Organización de Naciones Unidas para la Alimentación y la Agricultura (en adelante FAO por sus siglas en inglés) insta frecuentemente a los países a evitar los monocultivos y la ganadería extensiva como medidas para proteger la biodiversidad $^{44}$.

Estos y otros argumentos fueron empleados en la fundamentación del recurso de inconstitucionalidad presentado por Cedenma, Acción Ecológica y Libera contra el COA el día 5 de junio de $2018^{45}$.

\subsubsection{FALTA DE TÉCNICA}

El COA a lo largo de todo su texto y en materia forestal contiene varios ejemplos de falta de técnica. El artículo que mejor ejemplifica esta afirmación es el 124 que contiene al menos tres errores como se explica a continuación.

Artículo 124.- De los sistemas agroforestales. Los sistemas agroforestales y los árboles de la regeneración natural orientarán sus actos de la siguiente forma:

1. Solo califican como sistemas agroforestales aquellas combinaciones de especies forestales y cultivos que cuenten con suficiente densidad de árboles, conforme con las normas técnicas de la materia; $[\ldots]$

38 En caso de interés en profundizar en los elementos y alcances del Plan de Ordenamiento Territorial se recomienda revisar el Código Orgánico de Ordenamiento y Desarrollo Territorial (COOTAD. Registro Oficial No. 303 Suplemento de 19 de octubre de 2010.)

39 "Desertificación (Desertification).- Proceso de modificación lenta y continua del ambiente hacia condiciones cada vez más secas, en las que la aridez responde a los cambios en el balance hídrico, la reducción de la tabla freática y del contenido de planteas, que se hacen cada vez más seas y escasa, con el consiguiente abandono de los animales.

La reducción de la diversidad y la escasez de agua son dos parámetros que establecen el «avance del desierto»". (Sarmiento, Fausto. Óp. cit.)

40 SER. Sociedad para la Restauración Ecológica. Página web https://www.ser.org/default.aspx

41 Van Andel, Jelte y Aronson, James. Restoration Ecology: The New Frontier. Oxford: Blackwell, 2012.

42 La molestia es un factor que causa un cambio o transformación en la estabilidad de un ecosistema desde una molestia ligera hasta antes de cruzar el umbral no reversible que hace la autorrecuperación imposible.

43 Resistencia es la capacidad del ecosistema de absorber una perturbación sin pérdidas de funcionalidad ecológica.

$44 \mathrm{FAO}$ web oficial www.fao.org/home/es/. Última fecha de consulta: 25 de noviembre de 2018.

45 Boletín y rueda de prensa de la presentación de la acción de inconstitucionalidad presentado contra el COA el día 5 de junio de 2018 puede consultarse en: https://www.facebook.com/CEDerechosHUmanos/videos/1688490821233527/. Fecha de la descarga: 25 de noviembre de 2018. 
5. Tratándose de cortinas antierosivas o rompevientos, entendidas como sistemas de protección de cobertura, solo es permitido el raleo o la entresaca de individuos en un grado que garantice la continuidad de sus funciones protectoras.

Fácilmente puede notarse que el encabezado del artículo 124 contiene una barbaridad jurídica, al asumir que los sistemas agroforestales y los árboles deben orientar sus actos hacia determinado fin. Resta decir que sistemas agroforestales y árboles carecen de la capacidad jurídica y decisión adoptada con libre albedrío para orientar sus actos en forma alguna.

El segundo ejemplo de falta de técnica es el relativo al sistema agroforestal, que no es definido en el glosario de la ley y sobre el que trata el numeral 1 del artículo 124.

Un sistema agroforestal es el conjunto funcional de elementos agrícolas y forestales integrados por factores que los interrelacionan, creando dependencias intrínsecas o extrínsecas que definen su estructura o su función, concretamente incluye "el manejo de áreas originalmente forestadas con el objetivo de obtener rendimientos de cultivos y de madera sin detrimento de los recursos de suelos y de vida silvestre originalmente" ${ }^{46}$. El agroforestal es un sistema de uso integral del suelo donde especies leñosas perennes, por ejemplo, árboles, arbustos, palmas, bambúes o enredaderas, interactúan biológica y económicamente en una misma área con cultivos agrícolas y/o animales ${ }^{47}$. Estos elementos pueden estar asociados en forma simultánea o secuencial, en zonas o mezclados.

Puede afirmarse que la densidad de los árboles (y otros leñosos) es solo un elemento del sistema agroforestal, pero técnicamente no es elemento que define si el sistema es o no agroforestal. Cabe preguntarse a qué agenda le es de interés que existan sistemas agroforestales que, por no alcanzar determinada densidad, no sean calificados como tales.

El tercer error se encuentra en el numeral 5 del artículo 124 que trata sobre las cortinas antierosivas $^{48}$ y sobre el raleo; ninguno de los dos está definido en el glosario. Este último consiste en la eliminación o poda de una proporción de los árboles que interfieren en el crecimiento de otros por problemas de crecimiento, orientación o forma; generalmente el primer raleo es para desechar árboles jóvenes que entorpecen otros, y los demás raleos tienen finalidades comerciales (dejar en pie los mejores individuos) o para el manejo general.

46 Sarmiento, Fausto, Óp. cit.

47 Ibid.

48 "Cortina rompeviento (Wind Breaker).- Disposición linear de árboles plantados en fila a lo largo de los linderos de pastizales o terrenos de labor con el fin de frenar el impacto del viento sobre los cultivos. Árboles de alargado talle y de fronda reducida son preferidos a los ejemplares frondosos para que la resistencia sea ejercida por la ubicación de las filas arboladas y no por la ubicación de las filas". (Ibid.) 
Como consta en la cita textual del artículo 124, este promueve el raleo. Sin embargo, siendo las cortinas antierosivas una "disposición linear de árboles plantados en fila a lo largo de los linderos de pastizales o terrenos de labor con el fin de frenar el impacto del viento sobre los cultivos" ${ }^{\prime 4}$, en la práctica son perímetros o líneas de árboles que difícilmente podrían requerir raleo porque la densidad en una barrera forestal que se encuentra en línea limítrofe de árboles es baja. Vale decir que nunca sería ni mínimamente similar a la densidad de una plantación.

Atendiendo a la norma estrictamente, parecería más bien que la entresaca en una cortina rompeviento permitiría un aprovechamiento forestal antes de que los árboles hayan alcanzado su madurez fisiológica; objetivo distinto de aquel de protección que tiene la cortina.

\subsubsection{NIVEL DE LA NORMA}

El artículo 156 del COA contiene una norma que parece más bien propia de una ordenanza que de un cuerpo orgánico ${ }^{50}$.

Esta misma norma podría ser vista como intromisión del ejecutivo central en las competencias ambientales que los gobiernos autónomos descentralizados (en adelante GAD) tienen garantizadas en el Código Orgánico de Organización Territorial, Autonomía y Descentralización (en adelante COOTAD) ${ }^{51}$.

En lugar de favorecer la articulación entre niveles y autoridades como disponen los numerales $6^{52}$ y $7^{53}$ del artículo 8 , este texto más bien parece propiciar problemas de competencias por intromisión.

49 Ver nota al pie No. 32 que contiene la definición completa.

50 "Art. 156.- Del censo del arbolado urbano. Dentro del cálculo y medición del área verde urbana, los Gobiernos Autónomos Descentralizados Municipales o Metropolitanos podrán incorporar un registro del número de árboles, tanto por habitante como por unidades territoriales. Para el mismo objetivo, podrán llevar un censo periódico y georreferenciado de la tipología de árboles existentes, de sus características dasométricas, del número de individuos y de la cantidad de especies nativas e introducidas presentes.

Este censo deberá establecer también el potencial urbano para incrementar el número de árboles en la ciudad. Toda la información generada será remitida al Sistema Único de Información Ambiental para su sistematización y publicación”. (COA. Eiusdem. Artículo 156.)

51 COOTAD. Eiusdem.

52 "Art. 8.- Responsabilidades del Estado. Sin perjuicio de otras establecidas por la Constitución y la ley, las responsabilidades ambientales del Estado son: [...]

6. Instaurar estrategias territoriales nacionales que contemplen e incorporen criterios ambientales para la conservación, uso sostenible y restauración del patrimonio natural, los cuales podrán incluir mecanismos de incentivos a los Gobiernos Autónomos Descentralizados por la mejora en sus indicadores ambientales; así como definir las medidas administrativas y financieras establecidas en este Código y las que correspondan; y,". (COA. Eiusdem. Artículo 8 numeral 6.)

53 "Art. 8.- Responsabilidades del Estado. Sin perjuicio de otras establecidas por la Constitución y la ley, las responsabilidades ambientales del Estado son: $[\ldots]$

7. Garantizar que las decisiones o autorizaciones estatales que puedan afectar al ambiente sean consultadas a la comunidad, a la cual se informará amplia y oportunamente, de conformidad con la Constitución y la ley. La planificación y el ordenamiento territorial son unas de las herramientas indispensables para lograr la conservación, manejo sostenible y restauración del patrimonio natural del país. Las políticas de desarrollo, ambientales, sectoriales y nacionales deberán estar integradas". (Eiusdem. Artículo 8 numeral 7.) 


\subsubsection{MANGLAR}

La condición de megadiversidad del Ecuador, que se aludió anteriormente, se debe en parte a la presencia del ecosistema manglar ${ }^{54}$, que es lamentablemente un hábitat en constante peligro por las actividades no sostenibles que se efectúan en él.

El COA, en lugar de procurar conservar los manglares y promover alianzas sociales y locales para garantizar esta conservación, autoriza la construcción de infraestructura. Lo hace su artículo 104 numeral $7^{55}$ que incluye "otras actividades productivas o de infraestructura pública", cuya única limitación, según el texto legal, es contar con autorización expresa de la Autoridad Ambiental Nacional y ofrecer programas de reforestación.

Ni la ejecución de obras productivas ni la construcción de obras de infraestructura son compatibles con el principio constitucional de no regresividad de los derechos ${ }^{56}$ en vista que la anteriormente vigente Ley Forestal y de Conservación de Áreas Naturales y Vida Silvestre disponía que los manglares como bienes del Estado podían únicamente ser explotados por vía de contrato de concesión. ${ }^{57}$ Debido a que la ley anterior no incluía la posibilidad de otorgar permisos "otras actividades productivas o de infraestructura pública” y el COA, sí lo hace, es un evidente caso de retroceso en la protección para este ecosistema porque la legislación anterior disponía un mejor nivel de protección.

La consideración que tenía la legislación anterior contra las actividades productivas y las obras de infraestructura se fundamentaba en que ambas provocan serios daños en el ecosistema manglar además de daños colaterales producidos por la escala de la actividad productiva, la dimensión de la construcción, los materiales y las técnicas empleados, el carácter temporal o permanente de la actividad u obra y el movimiento de tierras que ambas requieren, entre otros aspectos.

54 La península ecuatoriana tiene veintiún de los veintisiete ecosistemas marinos y costeros mundialmente reconocidos como importantes para la conservación de la biodiversidad (diez de los catorce marinos y once de los trece ecosistemas costeros).

55 "Art. 104.- Actividades permitidas en el ecosistema de manglar. Las actividades permitidas en el ecosistema de manglar, a partir de la vigencia de esta ley, serán las siguientes: $[\ldots]$

7. Otras actividades productivas o de infraestructura pública que cuenten con autorización expresa de la Autoridad Ambiental Nacional y que ofrezcan programas de reforestación". (Eiusdem. Artículo 104.)

56 "Título II: Derechos. Capítulo Primero: Principios de Aplicación de los Derechos.

Art. 11.- El ejercicio de los derechos se regirá por los siguientes principios: [...]

8. El contenido de los derechos se desarrollará de manera progresiva a través de las normas, la jurisprudencia y las políticas públicas. El Estado generará y garantizará las condiciones necesarias para su pleno reconocimiento y ejercicio. Será inconstitucional cualquier acción u omisión de carácter regresivo que disminuya, menoscabe o anule injustificadamente el ejercicio de los derechos". (Constitución de la República del Ecudor. Eiusdem. Artículo 11.)

57 "Art. 1.- Constituyen patrimonio forestal del Estado, las tierras forestales que de conformidad con la Ley son de su propiedad, los bosques naturales que existan en ellas, los cultivados por su cuenta y la flora y fauna silvestres; los bosques que se hubieren plantado o se plantaren en terrenos del Estado, exceptuándose los que se hubieren formado por colonos y comuneros en tierras en posesión. Las tierras del Estado, marginales para el aprovechamiento agrícola o ganadero. Todas las tierras que se encuentren en estado natural y que por su valor científico y por su influencia en el medio ambiente, para efectos de conservación del ecosistema y especies de flora y fauna, deban mantenerse en estado silvestre. Formarán también dicho patrimonio, las tierras forestales y los bosques que en el futuro ingresen a su dominio, a cualquier título, incluyendo aquellas que legalmente reviertan al Estado.

Los manglares, aun aquellos existentes en propiedades particulares, se consideran bienes del Estado y están fuera del comercio, no son susceptibles de posesión o cualquier otro medio de apropiación y solamente podrán ser explotados mediante concesión otorgada, de conformidad con esta Ley y su reglamento." Ley Forestal y de Conservación de Áreas Naturales y Vida Silvestre (derogada por el COA). Registro Oficial Suplemento 418 de 10 de septiembre de 2004. 
En tratándose del tema de la regresividad del código en materia de manglares, hay otros dos aspectos adicionales.

De un lado, el cuerpo legal implica una regresión respecto del uso privilegiado que se concedía a las comunidades ancestrales como mecanismo de manejo participativo con fines de conservación que se consagraba en el Texto Unificado de Legislación Secundaria del Ministerio del Ambiente (en adelante Tulsma) ${ }^{58}$.

De otro, esta última norma prohibía la instalación de fábricas e infraestructura, al igual que cualquier actividad que produjera desechos tóxicos. ${ }^{59}$ Concretamente, en cuanto a la actividad camaronera, el Tulsma determinaba la necesidad de un inventario de las piscinas camaroneras existentes ${ }^{60}$ (al momento de la entrada en vigencia de la norma) con el objeto de impedir la autorización de construcción de nuevas piscinas o ampliación de las camaroneras ya existentes a esa fecha ${ }^{61}$.

Vale reiterar que el COA, al permitir que se efectúen "otras actividades productivas" en el manglar, permitiría la autorización de nuevas piscinas camaroneras, actividad prohibida por una norma. Si bien es cierto la norma anterior (Tulsma) es secundaria, su fundamento era una ley, la Forestal y de Conservación. En tal sentido, existe de forma absoluta un caso contra el principio de no regresividad ${ }^{62}$.

\subsubsection{CuenCaS hidrográficas}

Como corpus ambiental, un vacío sensible en el instrumento analizado es el relativo a las cuencas hidrográficas. No solo no las define en su glosario, sino que además contiene una incongruencia en el artículo 5 numeral $4^{63}$ porque el texto incluye la posibilidad de recuperar recursos hídricos, lo cual no es técnicamente posible.

58 "Libro V: Recursos Marinos Costeros

Art. 19.- Será de interés público la conservación, protección y reposición de los bosques de manglar existentes en el país, de conformidad a lo dispuesto en el artículo 12 de la Ley Forestal y de Conservación de Áreas Naturales y Vida Silvestre. En consecuencia, prohíbase su explotación y tala.

Sin embargo, las comunidades ancestrales podrán solicitar se les conceda el uso sustentable del manglar para su subsistencia, aprovechamiento y comercialización de peces, moluscos y crustáceos, entre otras especies, que se desarrollen en este hábitat. Tales solicitudes de las comunidades ancestrales y usuarios ancestrales serán atendidas mediante el otorgamiento del «Acuerdo de Uso Sustentable y Custodia del Manglar», que será emitido por el Ministerio de Medio Ambiente a través de la Subsecretaría de Desarrollo Sostenible con sede en Guayaquil.

Las comunidades y usuarios favorecidos con el «Acuerdo de Uso Sustentable y Custodia del Manglar» tendrán la obligación de cuidar este ecosistema y comunicar a la autoridad competente, de cualquier violación o destrucción del mismo". (Texto Unificado de Legislación Secundaria de Medio Ambiente (Tulsma). Artículo 19. Decreto Ejecutivo No. 3516, Registro Oficial No. 2 Edición Especial de 31 de marzo de 2003, Última modificación: 29 de marzo de 2017.)

59 "Art. 52.- De la misma manera, no se permitirá en las áreas del ecosistema de manglar la instalación de fábricas e infraestructura y actividades que produzcan desechos tóxicos, de acción residual que ponga en peligro el ecosistema y su biodiversidad”. (Eiusdem. Artículo 52.)

60 "Art. 53.- Las piscinas camaroneras construidas en el ecosistema de manglar, serán inventariadas y delimitadas por la Subsecretaría de Gestión Ambiental Costera, con la colaboración de la Digmer y la Dirección General de Pesca, cada dos años”. (Eiusdem. Artículo 53.)

61 "Art. 54.- No se autorizará por parte de ninguna entidad u organismo del Estado, la construcción de nuevas piscinas o la ampliación de las camaroneras existentes en el ecosistema de manglar y su zona de transición”. (Eiusdem. Artículo 54.)

62 En caso de interés en profundizar en el análisis constitucional de este aspecto se recomienda la revisión de la Acción de inconstitucionalidad contra el COA presentada por Cedenma y otros el día 5 de junio de 2018.

63 "Artículo 5.- Derecho de la población a vivir en un ambiente sano. El derecho a vivir en un ambiente sano comprende: [...] 4. La conservación y recuperación de los recursos hídricos, cuencas hidrográficas y caudales ecológicos asociados al ciclo hidrológico". (Eiusdem. Artículo 5.) 
La recuperación es posible en las cuencas hidrográficas; mismas que también son susceptibles de manejo porque, en un sentido netamente físico, son espacios delimitados por límites topográficos, donde la precipitación escurre hacia un solo punto; por esto la cuenca en sí permanece y lo que cambia y se degrada son los recursos que en ella se desarrollan (agua principalmente).

Acto seguido y más importante aún es la sospechosa ausencia de competencia de la autoridad nacional ambiental sobre las cuencas hidrográficas. Entre las atribuciones de esta autoridad en el artículo veinticuatro ${ }^{64}$ no consta ninguna relacionada a cuencas hidrográficas como unidad básica de planificación y administración ambiental, ni siquiera para guardar coherencia con el artículo 5 numeral 4 ya mencionado.

\subsubsection{REPARACIÓN DE DAÑOS AMBIENTALES}

El COA trae consigo un tema de conflicto con otro cuerpo orgánico, el Código Orgánico General de Procesos ${ }^{65}$ (en adelante COGEP) en materia de la reparación ambiental integral frente a la restauración. Los textos implicados son los artículos 296 del primero ${ }^{66}$ y 39 del COGEP ${ }^{67}$.

64 "Art. 24.- Atribuciones de la Autoridad Ambiental Nacional.- La Autoridad Ambiental Nacional tendrá las siguientes atribuciones: 1. Emitir la política ambiental nacional;

2. Establecer los lineamientos, directrices, normas y mecanismos de control y seguimiento para la conservación, manejo sostenible y restauración de la biodiversidad y el patrimonio natural;

3. Emitir criterios y lineamientos, en coordinación con la Autoridad Nacional competente de la Planificación Nacional, para valorar la biodiversidad, sus bienes y servicios ecosistémicos, su incidencia en la economía local y nacional, así como internalizar los costos derivados de la conservación, restauración, degradación y pérdida de la biodiversidad;

4. Ejercer la rectoría del Sistema Nacional Descentralizado de Gestión Ambiental;

5. Emitir lineamientos y criterios para otorgar y suspender la acreditación ambiental, así como su control y seguimiento;

6. Otorgar, suspender, revocar y controlar las autorizaciones administrativas en materia ambiental en el marco de sus competencias;

7. Declarar las áreas que se integrarán a los subsistemas del Sistema Nacional de Áreas Protegidas, y definir las categorías, lineamientos, herramientas y mecanismos para su manejo y gestión;

8. Establecer las listas de especies de vida silvestre con alguna categoría de amenaza, en base a las prioridades de conservación y manejo a escala nacional o los instrumentos o tratados internacionales ratificados por el Estado;

9. Repatriar colecciones ex situ de especies de vida silvestre traficadas, así como las especies decomisadas en coordinación con la autoridad correspondiente. Cuando sea posible se procederá con la reintroducción de dichas especies;

10. Delimitar dentro del Patrimonio Forestal Nacional las tierras de dominio público y privado y adjudicar a sus legítimos posesionarios de acuerdo con la ley;

11. Realizar y mantener actualizado el inventario forestal nacional, la tasa de deforestación y el mapa de ecosistemas;

12. Crear, promover e implementar los incentivos ambientales;

13. Emitir lineamientos y criterios, así como diseñar los mecanismos de reparación integral de los daños ambientales, así como controlar el cumplimiento de las medidas de reparación implementadas;

14. Definir la estrategia y el plan nacional para enfrentar los efectos del cambio climático en base a la capacidad local y nacional;

15. Fijar y cobrar las tarifas, tasas por servicios, autorizaciones o permisos y demás servicios en el ámbito de su competencia;

16. Conocer, tramitar, investigar y resolver las quejas y denuncias;

17. Ejercer la potestad sancionatoria y la jurisdicción coactiva en el ámbito de su competencia, así como conocer y resolver los recursos administrativos que se interpongan respecto de las resoluciones de los órganos desconcentrados; y,

18. Las demás que le asigne este Código y las normas aplicables”. (Eiusdem. Artículo 24.)

65 Código Orgánico General de Procesos (COGEP). Registro Oficial No. 506 Segundo Suplemento de 22 de mayo de 2015.

66 "Art. 296.- Aprobación de las medidas de reparación. La Autoridad Ambiental Competente deberá aprobar las medidas de reparación integral presentadas por el responsable del daño ambiental y su respectiva implementación. La aprobación de las medidas ejecutadas que no hayan reparado integralmente los dańos ambientales será nula de pleno derecho.

En caso de incumplimiento de la reparación integral aprobada por la Autoridad Ambiental Competente, las personas naturales y jurídicas, o las comunas, comunidades, pueblos y nacionalidades, podrán ejercer las acciones por la vía judicial”. (COA. Eiusdem. Artículo 296.)

67 "Título III: Sujetos del Proceso. Capítulo II: Representación de la Naturaleza

Artículo 39.- Medidas. Si por aplicación de otras leyes se hubiera conseguido prevenir, evitar, remediar, restaurar y reparar los dańos ambientales, no será necesario tramitar las acciones descritas en este capítulo.

Las medidas remediadoras, restauradoras y reparadoras de los daños ambientales, así como su implementación, se someterán a la aprobación de la autoridad ambiental nacional.

En el caso de que no existan tales medidas, la o el juzgador las ordenará”. (COGEP. Eiusdem. Artículo 39.) 
De un lado, el COGEP, con preminencia temporal, estableció que, en tratándose de la representación de la naturaleza, las medidas de remediación, restauración y reparación de dańos ambientales debían someterse a la aprobación de la autoridad ambiental nacional, y, en caso de inexistencia, quedaba al juez el ordenarlas.

Pero el COA, posteriormente, determina que, en caso de incumplimiento de las medidas de reparación integral, se requerirá que "personas naturales y jurídicas o las comunas, comunidades, pueblos y nacionalidades" demanden en vía judicial.

Lo primero que llama la atención es que el cuerpo legal analizado, pese a ser un instrumento especializado, ni siquiera enumere todas las opciones legales ante un daño ambiental y que solo defina la restauración ${ }^{68}$ dejando de lado a la remediación y a la reparación. Pero más llama la atención que, mientras el COGEP enfatiza en la falta de medidas y determina que las declare, el COA se refiera directamente al incumplimiento y no establezca fórmula de actuación en el caso de inexistencia de medidas.

También debe destacarse que una de las pocas luces del texto analizado está en este artículo, ya que reconoce que la demanda pueda ser presentada por un tercero cualquiera, posibilitándose la participación de "personas naturales y jurídicas o las comunas, comunidades, pueblos y nacionalidades" en acciones concretas en instancia judicial en reclamo de medidas de reparación integral por daño o contaminación.

\section{Conclusiones}

La diversidad biológica es uno de los recursos más abundantes del Ecuador; sin embargo, debido a que no ha sido apreciada como un recurso estratégico para el desarrollo nacional, ha sido blanco de actividades productivas no amigables y por ello sus valores y servicios están en peligro, dentro y fuera de las áreas establecidas para su conservación y uso sustentable. Ante esta situación la legislación ecuatoriana poco o nada ha podido hacer por sus características normas dispersas y contradictorias, y por la poca e ineficiente aplicación por parte de autoridades ambientales siempre debilitadas, entre otras razones por la poca claridad de sus competencias y del sistema de relacionamiento con otras autoridades territoriales como los GAD.

En ese escenario, se habría esperado que la aparición de un código orgánico dedicado al ambiente resolviera varios problemas, pero no ha sido así. Lejos de ser una solución a la situación de indefensión jurídica de bienes y servicios ambientales, el COA provoca aún más problemas y más debilidad temática.

68 "Glosario. Restauración.- Conjunto de actividades tendientes a la recuperación y restablecimiento de las condiciones que propicien la evolución de los procesos naturales y mantenimiento de servicios ambientales". (COA. Eiusdem.) 
Esta investigación concluye que el COA es efectivamente un nuevo driver contra la conservación de la diversidad biológica. No es solo su falta de técnica sino también la intencionalidad de sus disposiciones, por ejemplo, en materia de regresividad, lo que hace que el COA sea un motor contra la conservación de la diversidad biológica.

Este instrumento legal no sirve como base para la institucionalidad ambiental que facilite compromisos institucionales y sociales enfocados al cambio del actual modelo de desarrollo. Tampoco permitirá consolidar compromisos y políticas públicas, así como contar con un rediseño del marco institucional y legal adecuado para la conservación y manejo de bienes y recursos de la diversidad biológica. Ello porque a pesar de que el COA integra varias piezas existentes de legislación ecuatoriana, es un cuerpo normativo que no guarda relación con principios técnicos de conservación, manejo y uso sustentable.

De otro lado, no puede esperarse una articulación eficientemente en el nivel de su aplicación, no solo porque aún no tiene reglamentos general y especiales de aplicación, sino también porque sus deficiencias no lo permitirán. El COA deja sin definición demasiados temas que, por las limitaciones de este trabajo de investigación, no fueron enlistados y lo serán en un próximo trabajo; sin embargo, se ha ejemplificado el caso de los manglares y de las cuencas hidrográficas y se mencionó la falta de definición de los subsistemas y las categorías de áreas protegidas que integran cada nivel. Estos y otros quedan librados a normas reglamentarias secundarias y técnicas, lo cual incumple con la técnica y atenta contra la seguridad jurídica. Sobra decir que lo que el COA no manda, permite o prohíbe no puede ser objeto ni de reglamento ni de norma técnica.

El COA mantiene una óptica reduccionista y sectorialista sobre temas ambientales relevantes para la conservación como, por ejemplo, el caso de la conservación de los manglares. El texto legal no consideró adecuadamente la información técnica disponible y por ello los elementos de relevancia e interrelación natural y social no son debidamente tratados; igual puede decirse sobre los principios orientadores de la participación de otras entidades públicas y privadas bajo el liderazgo de la autoridad ambiental nacional, el MAE, que lejos de fortalecerla, la debilitan. 


\section{AneXo No. 1: Resumen DE DISPOSICIONES DEL COA}

\begin{tabular}{|c|c|c|}
\hline Disposición & Número & Contenido / materia \\
\hline \multirow[t]{2}{*}{ Generales } & Primera & $\begin{array}{l}\text { Obligación de las instituciones del Sistema Nacional } \\
\text { Descentralizado de Gestión Ambiental de entregar } \\
\text { información al MAE. }\end{array}$ \\
\hline & Segunda & $\begin{array}{l}\text { Regla sobre el carácter obligatorio de las normas } \\
\text { ambientales en las provincias amazónicas y comple- } \\
\text { mentaria cuando se dicten leyes orgánicas especiales }\end{array}$ \\
\hline \multirow{7}{*}{ Transitorias } & Primera & $\begin{array}{l}\text { Los procedimientos administrativos y demás trámi- } \\
\text { tes iniciados o en proceso cumplirán con las leyes y } \\
\text { normas vigentes a la fecha de inicio del trámite. }\end{array}$ \\
\hline & Segunda & $\begin{array}{l}\text { Disposición de ajuste y actualización de las mallas } \\
\text { curriculares de educación para incluir los principios } \\
\text { y enunciados del COA en el plazo de un año. }\end{array}$ \\
\hline & Tercera & $\begin{array}{l}\text { Plazo de noventa días para que los Ministerios de Agri- } \\
\text { cultura (en adelante MAG), Educación, Salud, Am- } \\
\text { biente y Senescyt dicten los lineamientos y normas } \\
\text { técnicas para el manejo responsable de la fauna urbana }\end{array}$ \\
\hline & Cuarta & $\begin{array}{l}\text { Plazo de ciento ochenta días para los GAD muni- } \\
\text { cipales o metropolitanos dicten las normas para la } \\
\text { fauna y arbolado urbano }\end{array}$ \\
\hline & Quinta & $\begin{array}{l}\text { Plazo de ciento ochenta días para que los GAD mu- } \\
\text { nicipales o metropolitanos dicten las ordenanzas re- } \\
\text { lativas a la prohibición de las corridas de toros cuya } \\
\text { finalidad sea dar muerte al animal. } \\
\text { El mismo plazo se concede para la regulación de los } \\
\text { espectáculos que incluyan animales }\end{array}$ \\
\hline & Sexta & $\begin{array}{l}\text { Obligación del MAE para evaluar las AP que con- } \\
\text { forman el SNAP y Patrimonio Forestal Naciona } \\
\text { dentro de cuatro años y para delimitarlas o cambiar- } \\
\text { las de categoría. } \\
\text { En el caso del Patrimonio Forestal Nacional, se ac- } \\
\text { tuará en coordinación con el MAG y se realizará una } \\
\text { actualización para restaurar, modificar sus límites o } \\
\text { eliminarla del patrimonio. }\end{array}$ \\
\hline & Séptima & $\begin{array}{l}\text { Obligación del MAE de coordinar con el MAG y los } \\
\text { Registros de la Propiedad la revisión, verificación y } \\
\text { levantamiento de información de la propiedad o po- } \\
\text { sesión en las AP y del Patrimonio Forestal Nacional. } \\
\text { En noventa días, el MAE en coordinación con el } \\
\text { MAG definirá el procedimiento para la legalización } \\
\text { de tierras en AP y Patrimonio Forestal Nacional. }\end{array}$ \\
\hline
\end{tabular}




\begin{tabular}{|c|c|c|}
\hline Disposición & Número & Contenido / materia \\
\hline Transitorias & Octava & $\begin{array}{l}\text { En un año, el MAE y los GAD actualizarán los ins- } \\
\text { trumentos que se requiera para el cumplimiento del } \\
\text { COA. } \\
\text { Los GAD acreditados que hayan expedido norma- } \\
\text { tiva ambiental deberán adecuar su contenido a estas } \\
\text { disposiciones. }\end{array}$ \\
\hline \multirow{9}{*}{ Reformatorias } & Primera & Reformas a la Ley Orgánica de Salud \\
\hline & Segunda & Reformas a la Ley de Caminos \\
\hline & Tercera & $\begin{array}{l}\text { Reformas a la Ley de Comercialización y Empleo de } \\
\text { Plaguicidas }\end{array}$ \\
\hline & Cuarta & $\begin{array}{l}\text { Reformas a la Código Orgánico de Organización } \\
\text { Territorial }\end{array}$ \\
\hline & Quinta & \multirow{3}{*}{ Reformas al Código Civil } \\
\hline & Sexta & \\
\hline & Séptima & \\
\hline & Octava & \multirow{2}{*}{ Reformas a la Ley de Minería } \\
\hline & Novena & \\
\hline \multirow{5}{*}{ Derogatorias } & Primera & Derogatoria de la Ley de Gestión Ambiental. \\
\hline & Segunda & $\begin{array}{l}\text { Derogatoria de la Ley para la Prevención y Control } \\
\text { de la Contaminación Ambienta }\end{array}$ \\
\hline & Tercera & $\begin{array}{l}\text { Derogatoria de Codificación de la Ley que Protege } \\
\text { la Biodiversidad en el Ecuador }\end{array}$ \\
\hline & Cuarta & $\begin{array}{l}\text { Derogatoria de Codificación de la Ley para la Preser- } \\
\text { vación de Zonas de Reserva y Parques Nacionales }\end{array}$ \\
\hline & Quinta & $\begin{array}{l}\text { Derogatoria de los Arts. 114, 115, } 116 \text { y } 149 \text { de la } \\
\text { Ley Orgánica de la Salud }\end{array}$ \\
\hline \multirow{2}{*}{ Derogatorias } & Sexta & $\begin{array}{l}\text { Derogatoria de la Codificación de la Ley Forestal y } \\
\text { de Conservación de Âreas Naturales y Vida Silvestre }\end{array}$ \\
\hline & Séptima & $\begin{array}{l}\text { Derogatoria del inciso 4to. del Art. } 3 \text { de la Ley de } \\
\text { Hidrocarburos }\end{array}$ \\
\hline $\begin{array}{l}\text { Disposición } \\
\text { final }\end{array}$ & Única & Se establece la vacatio legis del COA por un año \\
\hline
\end{tabular}

